\title{
Social Identity and the Formation of Health Insurance Networks*
}

\author{
Joachim De Weerdt ${ }^{\dagger}$ \\ EDI
}

\author{
Marcel Fafchamps \\ University of Oxford ${ }^{\ddagger}$
}

June 2010

\begin{abstract}
In a panel survey of an informal insurance network in Tanzania we find none of the telltale signs that insurance transfers follow reciprocal risk sharing arrangements among selfinterested individuals: insurance remittances do not occur through informal loans; transfers are not regressive; and they do not fall when shocks are repeated over time. The evidence of unreciprocated transfers occurring between kin is suggestive of risk sharing based on altruism or social norms.
\end{abstract}

JEL codes:

Keywords: mutual insurance; health risk; social capital

\footnotetext{
${ }^{*}$ We benefited from useful comments from two anonymous referees, Eliana La Ferrara, Stefan Dercon, and seminar participants at Bocconi and Oxford University. We thank FWO-Vlaanderen for their financial support in collecting the data and the people of Nyakatoke for their willingness to provide them. The support of the Economic and Social Research Council (UK) is also gratefully acknowledged. The work is part of the programme of the ESRC Global Poverty Research Group. The usual disclaimer applies.

${ }^{\dagger}$ Economic Development Initiatives (EDI), P.O. Box 393, Bukoba, Tanzania. E-mail: j.deweerdt@edi - africa.com

${ }^{\ddagger}$ Department of Economics, University of Oxford, Manor Road, Oxford OX1 3UQ. Email: marcel.fafchamps@economics.ox.ac.uk. Fax: +44(0)1865-281447. Tel: +44(0)1865-281446.
} 


\section{Introduction}

Empirical research has brought to light the role that gifts and transfers play in the sharing of risk (e.g. Rosenzweig 1988, De Weerdt and Dercon 2006, Fafchamps and Lund 2003). This research

has also demonstrated that risk is not shared efficiently, probably because of a combination of self-enforcement constraints, genetic limits to altruism, and the bounded reach of social networks (e.g. Altonji, Hayashi and Kotlikoff 1997, Townsend 1994, Platteau and Abraham 1987, Foster and Rosenzweig 2001, Bloch, Genicot and Ray 2004).

The literature on risk sharing has paid particular attention to the need for informal mutual insurance among non-altruistic individuals to be self-enforcing (e.g. Coate and Ravallion 1993, Ligon, Thomas and Worrall 2001). Self-enforcement relies on a quid pro quo: help is provided today in exchange for the credible promise of future reciprocity. Mutual assistance based on self-enforcing reciprocity should thus be poor at providing insurance against long term shocks. For instance, if someone becomes disabled or chronically ill, this person's capacity to reciprocate decreases. This is especially true in an agrarian society where most work is physical in nature. This a priori casts serious doubt on the capacity of reciprocity-based arrangements to offer insurance against the income and welfare loss due to chronic illness - or any persistent or permanent shock.

The risk sharing literature stands in contrast with a long standing line of research emphasizing the redistributive role of transfers, such as remittances from migrant workers to spouse and relatives in the home village (e.g. Lucas and Stark 1985, Gubert 2002, Azam and Gubert 2006). In this literature, transfers are shown to often assist those less able to support themselves, such as the elderly. Work on child fostering brings to light the role of the extended family to deal with the loss of a parent (e.g. Akresh 2004, Evans 2004, Duflo 2003, Case, Paxson and Ableidinger 2003, Ksoll 2007). 
Drawing from both empirical traditions, this paper examines the extent to which intravillage gifts and transfers are effective in insuring against transitory and persistent health shocks. Using US data Cochrane (1991) found that he could not reject full insurance for illnesses lasting less than 100 days, but full insurance was rejected for longer illnesses. Our analysis is based on household panel data collected by one of the authors in Nyakatoke, a rural village in the Kagera Region of Tanzania. The sample covers all households in a village. Complete coverage ensures that we are not missing an essential source of intra-village insurance, such as a powerful or wealthy resident (e.g. Ellsworth 1989, Platteau 1995), and that full household survey and transfer data is available from both the sending and receiving parties. Second, each household was interviewed at short, regular intervals for a total number of 5 survey rounds in 1 year. That means the time in between rounds is roughly three quarters of what the above cited US study found to be the full insurance cut-off. This allows us to make a meaningful distinction between transitory and chronic health shocks.

Since two seminal articles by Jackson and Wolinsky (1996) and Bala and Goyal (2000), a new strand of literature on network formation has emerged. Krishnan and Sciubba (2006), Bramoulle and Kranton (2005) and Bloch et al. (2004) all model networks as consisting of bilateral links between agents. This stands in contrast with the previous literature according to which informal insurance takes place within a clearly delineated 'group' of people (e.g. a village). Following the new literature, the empirical analysis in this paper uses the dyad - or pair of households as unit of observation. Santos and Barrett (2007) discuss some of the problems involved when sampling network links. In our data, we observe all the links between village members.

Building on the work of De Weerdt (2004) and Fafchamps and Gubert (2007b), we use dyadic regressions to demonstrate the association between reported illness and transfers received. This relationship appears unaffected by the previous rounds' health shocks, suggesting that 
the association holds for both transitory shocks and more persistent shocks. Next, we look at disability and find that households with chronically disabled members are net transfer recipients, primarily from kin.

The theoretical literature has argued that self-enforcement constraints put limits on reciprocity and hence on the extent of risk sharing (e.g. Kimball 1988, Coate and Ravallion 1993, Ligon et al. 2001, Genicot and Ray 2003). These limitations can be partly overcome by altruism which, according to Hamilton's rule, is hypothesized to be correlated with blood ties and shared genes (see Cox and Fafchamps (2007) for details). This is consistent with our finding that kinship plays a paramount role in explaining transfers, especially those transfers where reciprocity is unlikely.

We also test two other tell-tale signs of binding self-enforcement. Fafchamps (2003) shows that, if absolute risk aversion falls with wealth, voluntary participation constraints lead to informal insurance arrangements in which the poor, on average, give more to the rich than they receive - i.e., they pay an insurance premium. He also shows that when voluntary participation constraints are binding, informal insurance naturally takes the form of informal loans rather than transfers. We investigate these two predictions and find them both rejected: in our data the poor on average receive transfers from the wealthy, not the opposite; and informal loans are not used to buffer health shocks, while transfers are.

The paper is organized as follows. The conceptual framework and testing strategy are presented in Section 2. The survey and data are presented in Section 3. Econometric results are presented in Section 4 and further discussed in Section 5. Section 6 concludes. 


\section{Conceptual framework}

Much of the literature on risk sharing has focused on transitory income shocks. When shocks are short-lived, assistance is not needed for long and parties to a risk pooling arrangement reverse roles often. As a result it is possible to construct self-enforcing mutual insurance contracts that rely on the promise of future reciprocity (e.g. Kimball 1988, Coate and Ravallion 1993).

This approach works well for short-lived health shocks. But it tends to break down for health shocks that are persistent - e.g., a chronic illness - or permanent - e.g., disability. To see this formally, consider a pair of agents who share health risk and have the same discount factor $\beta$. Both agents are assumed risk averse. Let utility $U_{i t}=u_{i}\left(c_{i t}+\tau_{i j t}-h_{i t}\right)$ where $c_{i t}$ denotes consumption expenditures (other than health-related expenses) at time $t$ and $\tau_{i j t}$ is a transfer received by $i$ from $j$ at $t$. By construction, $\tau_{j i t}=-\tau_{i j t}$. Following Cochrane (1991) $h_{i t} \geq 0$ denotes the value of a health shock; it includes loss of earnings, health expenses, and the equivalent variation of suffering. If there is no shock, $h_{i t}=0$. Without introducing explicit notation to keep the model as simple as possible, we imagine that health shocks are of different types. We define a shock as transitory if it contains no information regarding future shocks. If a shock today increases the likelihood of a shock later such that $\partial E_{t \mid h_{i t}}\left[h_{i, t+s}\right] / \partial h_{i t}>0$ for some $s>0$, this shock is called persistent. ${ }^{1}$ A permanent shock is such that $E_{t \mid h_{i t}}\left[h_{i, t+s}\right]=h_{i t} \forall s>0$. Disability resulting from an accident is an example of permanent shock. Since our focus is on health, we abstract from other shocks.

Given that agents are risk averse, it is mutually beneficial for $i$ and $j$ to share risk. This implies that there exist conditional transfer schemes that raise expected utility. To represent this formally, let $\boldsymbol{\tau}=\left\{\tau_{i j, t}, \tau_{i j, t+1}, \ldots\right\}$ denote such an arbitrary scheme. We do not impose any

\footnotetext{
${ }^{1} E_{t \mid h_{i t}}\left[h_{i, t+s}\right]$ denotes the expectation at time $t$ of $h_{i}$ at time $t+s$, conditional on knowing the value of the shock $h_{i}$ at time $t$.
} 
a priori restriction on conditionality except time consistency, i.e., $\tau_{i j t}$ can only depend on shocks up to and including time $t$ - not on shocks that have not occurred yet. A scheme that provides mutual insurance must satisfy: ${ }^{2}$

$$
E_{t}\left[F_{i}(t, \boldsymbol{\tau})\right] \geq 0
$$

with

$$
F_{i}(t, \boldsymbol{\tau}) \equiv \sum_{s=1}^{\infty} \beta^{s}\left\{u_{i}\left(c_{i, t+s}+\tau_{i j, t+s}-h_{i, t+s}\right)-u_{i}\left(c_{i, t+1}-h_{i, t+s}\right)\right\}
$$

A typical mutual insurance scheme will stipulate $\tau_{j i t} \geq 0$ whenever $j$ faces a (negative) health shock and $i$ does not, and vice versa.

It can be shown that, in an efficient scheme, transfers are only conditional on current shocks, not on past shocks. ${ }^{3}$ An immediate corollary is that a pair of shocks $\left(h_{i}, h_{j}\right)$ triggers the same transfer $\tau_{i j}$ irrespective of whether the shocks are transitory or permanent. An efficient scheme need not be self-enforcing, however. This is easily seen in the case of permanent shocks. Consider a transfer scheme stipulating that, if $i$ becomes disabled, $j$ will forever make transfers to him - and vice versa. As long as $i$ and $j$ are risk averse, this satisfies (1): it is in $i$ and $j$ 's ex ante interest to insure each other against disability. However, if $i$ truly becomes disabled, $j$ will want

\footnotetext{
${ }^{2}$ More precisely, each transfer $\tau_{i j, t}$ is conditional on health shocks at time $t$, and potentially conditional on shocks and/or transfers that took place before $t$.

${ }^{3}$ This follows from the condition for efficient risk sharing which requires the equalization of the ratio of marginal utilities $u_{i}^{\prime} / u_{j}^{\prime}$ across states of nature in all periods. This condition defines an implicit relationship between $\tau_{i j t}, h_{i t}$ and $h_{j t}$ in which past shocks play no role.

To illustrate this with a simple example, assume that consumption is constant and $u(c)=\log (c)$. Omitting time subscripts for readability, the efficient risk sharing condition becomes:$$
\frac{u_{i}^{\prime}\left(c_{i}+\tau_{i j}-h_{i}\right)}{u_{j}^{\prime}\left(c_{j}-\tau_{i j}-h_{j}\right)}=\frac{u_{i}^{\prime}\left(c_{i}\right)}{u_{j}^{\prime}\left(c_{j}\right)}
$$

Substituting $u^{\prime}(c)=1 / c$ yields:

Straightforward algebra yields:

$$
\begin{gathered}
c_{j}\left(c_{i}+\tau_{i j}-h_{i}\right)=c_{i}\left(c_{j}-\tau_{i j}-h_{j}\right) \\
\tau_{i j}=\frac{c_{j}}{c_{i}+c_{j}} h_{i}-\frac{c_{i}}{c_{i}+c_{j}} h_{j}
\end{gathered}
$$

In the special case where $c_{i}=c_{j}$ then $\tau_{i j}=\frac{h_{i}-h_{j}}{2}$. This shows that transfers only depend on the magnitude of the current shocks, irrespective of whether they are transitory or persistent. For a more complete characterization of efficient risk sharing, see for instance Townsend (1994).
} 
to renege on the scheme. This raises an enforcement issue.

If a conditional transfer scheme $\boldsymbol{\tau}$ cannot be externally enforced, it has to be self-enforcing. This means it must satisfy voluntary participation constraints of the form:

$$
u_{i}\left(c_{i t}-h_{i t}\right)-u_{i}\left(c_{i t}+\tau_{i j t}-h_{i t}\right) \leq E_{t \mid h_{i t}, h_{j t}}\left[F_{i}(t, \boldsymbol{\tau})\right]
$$

for all time periods and states of the world. A similar set of constraints must be satisfied for $j$. The left-hand side is the payoff $i$ derives from reneging on the transfer scheme after the health shocks $h_{i t}$ and $h_{j t}$ have been realized and conditional transfer $\tau_{i j t}$ has been set according to scheme $\boldsymbol{\tau}$. This payoff is positive for $i$ whenever $\tau_{i j t}<0$, that is, when $\boldsymbol{\tau}$ stipulates that agent $i$ transfer money to $j$. The right-hand side is $i$ 's expected future payoff from continued participation in transfer scheme $\boldsymbol{\tau}$. Let $\tau_{i j}^{\max }$ denote the maximum transfer that satisfies (3). Coate and Ravallion (1993) have shown that $\tau_{i j}^{\max }$ is a non-decreasing function of $E_{t \mid h_{i t}, h_{j t}}\left[F_{i}(t, \boldsymbol{\tau})\right]$ : the larger $E_{t \mid h_{i t}, h_{j t}}\left[F_{i}(t, \tau)\right]$ is, the larger is $\tau_{i j}^{\max }$. A similar point is made in Kocherlakota (1996) who uses a model of reciprocal risk sharing to show that persistence in income shocks hurts risk sharing. Although (3) focuses on health rather than income shocks, the same intuition applies. The literature has also shown that, when constraints (3) bind, constrained optimal transfers depend not only on current shocks but also on the history of past shocks - see Kocherlakota (1996) for details.

We now examine what predictions the above model makes regarding transitory and persistent shocks. ${ }^{4}$ The intuition is simple: while $i$ and $j$ may ex ante agree to mutually insure each other against permanent health shocks, once the shock is realized, they will be tempted to renege on

\footnotetext{
${ }^{4}$ The available empirical evidence on mutual insurance indicates that efficient risk sharing is not achieved, suggesting instead that participation constraints bind in practice (e.g. Ligon et al. 2001, Fafchamps and Lund 2003). For participation constraints not to bind and efficiency to be achieved, $\beta$ must be sufficiently close to 1 . Agents are not infinitely lived. The probability of death bounds $\beta$ strictly below 1 . This puts constraints on the extent of mutual insurance against transitory shocks that can be achieved in practice (e.g. Kimball 1988, Coate and Ravallion 1993, Kocherlakota 1996).
} 
their promise. In other words, a transfer scheme that insures perfectly against permanent health shocks is unlikely to self-enforcing.

We illustrate this intuition using an example a contrario, i.e., we start from a transfer scheme that stipulates equal (non-zero) transfers whether a shock is permanent or transitory and show that constraint (3) is harder to satisfy for permanent shocks. To keep the example simple, we assume that $c_{i t}$ and $c_{j t}$ are constant and we focus on states of the world where $h_{j t}=0$. Consider an efficient mutual insurance scheme $\boldsymbol{\tau}$ with $E_{t}\left[F_{j}(t, \tau)\right]>0$. In an efficient insurance scheme, transfers are only conditional on current shocks. It follows that, conditional on $h_{j t}=0$, any efficient risk scheme $\boldsymbol{\tau}$ must stipulate a transfer rule of the form $\tau_{i j t}=\alpha\left(h_{i t}\right)$ with $\alpha^{\prime} \geq 0$ and $\alpha\left(h_{i t}\right) \leq h_{i t} .^{5}$

We now consider what happens to $j$ 's voluntary participation constraints. Let $\alpha^{T}\left(h_{i t}\right)$ and $\alpha^{P}\left(h_{i t}\right)$ denote the largest function $\alpha\left(h_{i t}\right)$ that satisfies $j$ 's participation constraint for a transitory and permanent shock of size $h_{i t}$, respectively. We want to show that $\alpha^{P}\left(h_{i t}\right)<\alpha^{T}\left(h_{i t}\right)$. We first note that the left-hand side of (3) now simplifies to $u_{j}\left(c_{j}\right)-u_{j}\left(c_{j}-\alpha\left(h_{i t}\right)\right)>0$ : the higher $h_{i t}$ and $\alpha\left(h_{i t}\right)$, the higher $j$ 's incentive to defect from the scheme. Now consider what happens to $E_{t \mid h_{i t}, h_{j t}}\left[F_{i}(t, \boldsymbol{\tau})\right]$. If shock $h_{i t}$ is transitory, no information is revealed about future shocks and $E_{t \mid h_{i t}, h_{j t}}\left[F_{i}(t, \boldsymbol{\tau})\right]=E_{t}\left[F_{i}(t, \boldsymbol{\tau})\right]>0$. This means that (3) is satisfied for a small enough $\alpha\left(h_{i t}\right)$ given $h_{i t}$. This sets $\alpha^{T}\left(h_{i t}\right)$. If the shock $h_{i t}$ is permanent, $E_{t \mid h_{i t}, h_{j t}}\left[F_{i}(t, \boldsymbol{\tau})\right]<E_{t}\left[F_{i}(t, \boldsymbol{\tau})\right]$ because $j$ now expects to assist $i$ in the future as well. It immediately follows that $\alpha^{P}\left(h_{i t}\right)<\alpha^{T}\left(h_{i t}\right)$. This completes the proof a contrario: a transfer scheme that efficiently stipulates equal transfers for a shock $h_{i t}$, irrespective of whether this shock is transitory or permanent, is less likely to be self-enforcing than a scheme that stipulates lower transfers for permanent shocks. This observation forms the basis of our estimation strategy.

\footnotetext{
${ }^{5}$ When utility is logarithmic and consumption levels are constant, function $\alpha\left(h_{i t}\right)$ takes the simple form $\alpha h_{i j t}$ with $\alpha=\frac{c_{j}}{c_{i}+c_{j}}$.
} 
A similar argument applies to persistent shocks: the more persistent the shock is, the smaller $E_{t \mid h_{i t}, h_{j t}}\left[F_{i}(t, \boldsymbol{\tau})\right]$ is relative to $E_{t}\left[F_{i}(t, \boldsymbol{\tau})\right]$ for a given efficient scheme $\boldsymbol{\tau}$, and the smaller $\alpha^{\max }$ is relative to $\alpha^{T}\left(h_{i t}\right)$. Agents may not immediately realize a shock is persistent, however. For instance, this realization may only come when the shock is repeated in subsequent periods. In this case $E_{t \mid h_{i t}, h_{j t}}\left[F_{i}(t, \tau)\right]$ falls as the shock is repeated and more information is learned about the nature of the shock. This could be described as 'donor fatigue': repeated shocks trigger decreasing transfers. We discuss this more in detail below.

A similar reasoning holds for shocks that have a lasting negative effect on productive assets. The longer the shock and its effect last, the less likely parties are to reverse roles. This undermines the role of future reciprocity as an enforcement mechanism. Insurance against persistent health shocks looks, ex post, more like redistribution than like a reciprocal arrangement where parties switch roles over time. The question then is: how can individuals secure insurance against persistent shocks without the promise of future reciprocity?

One natural answer is altruism, that is, giving without the expectation of reciprocity by the gift recipient. Given the nature of the data, we cannot distinguish between different sources of altruism, e.g., whether driven by affection, upbringing, or social norms. For instance, if children systematically give to their parents with no expectation of reciprocity, for the purpose of this paper we call this altruism.

Following Dawkins (1989)' thought-provoking book on the selfish gene, a literature has emerged that seeks to test the relationship between altruism and genetic proximity. The evidence so far is generally consistent with the hypothesis that altruism is stronger the more genes people share in common (see Cox and Fafchamps (2007) for a review). We therefore expect close blood ties to be associated with stronger protection against long-term health shocks. It has also been suggested that identification with a group serves to reinforce altruistic tendencies. If true, 
this would mean that insurance against long-term health shocks is strongest among members of strongly identified groups drawn along the lines of clans, religions or neighbourhoods.

Altruism can be formally introduced in our model by assuming that agent $i$ derives subjective satisfaction $A_{i j}$ from helping $j$ with $A_{i j}$ an increasing function of how genetically close $i$ is to $j$. The participation constraint now is:

$$
u_{i}\left(c_{i t}-h_{i t}\right)-u\left(c_{i t}+\tau_{i j t}-h_{i t}\right) \leq E_{t \mid h_{i t}, h_{j t}}[F(t, \tau)]+A_{i j}
$$

It follows that the maximum achievable transfer $\tau_{i j}^{\max }$ is an increasing function of $A_{i j}$ and thus of how close $i$ is to $j$. If risk sharing is based purely on altruism $A_{i j}$, the promise of future reciprocity $E_{t \mid h_{i t}, h_{j t}}[F(t, \tau)]$ does not matter: $\tau_{i j}^{\max }$ only depends on the strength of $A_{i j}$. It follows that altruistic agents are willing to make transfers even without the credible promise of reciprocity - e.g., they care for elderly parents or disabled relatives. ${ }^{6}$

Risk pooling can also lead to redistribution, a point that has been noted by many authors and is discussed for instance by Fafchamps (2003). The reason is that risk averse individuals are willing to pay for insurance, and thus may voluntarily enter into risk sharing arrangements in which they expect to pay, on average, more than they receive. To illustrate the issue, let us momentarily focus on income shocks alone. Define an insurance contract as actuarially fair if $E\left[c_{i}\right]=E\left[y_{i}\right]$ where $c_{i}$ and $y_{i}$ denote the consumption and income of individual $i$, respectively. An actuarially fair contract is non-redistributive ex ante. Standard insurance contracts fail this condition whenever the insurance company makes a profit, which is normally the case. Platteau (1995) provides examples of patronage-based risk sharing that violates actuarial fair-

\footnotetext{
${ }^{6}$ Inter-generational transfers can in principle be supported by a subgame perfect equilibrium in which transfers given by one generation to their parents is sustained by the promise of future transfers from their children. This equilibrium is not based on the expectation that parents themselves will reciprocate and thus, for the purpose of this paper, falls under our broad definition of altruism.
} 
ness. Fafchamps (1999) shows that, with decreasing absolute risk aversion, self-enforcement constraints naturally lead to asymmetrical risk sharing whereby the poor give more, on average, to the wealthy than they receive. The reason is that the wealthy, who can self-insure, must be compensated for providing insurance to poorer members of society. Mutual insurance arrangements based on reciprocity and self-interest naturally result in regressive redistribution.

\subsection{Health shocks and transfers}

The purpose of this paper is to investigate these ideas empirically. We begin by testing whether gifts and transfers serve as insurance against transitory and persistent health shocks and whether

they have a systematic redistributive component, that is, flow from the wealthy to the poor or vice versa. We proceed using the dyadic regression framework developed by Fafchamps and Gubert (2007b).

Formally, let $\tau_{i j t}$ denote the transfer received by $i$ from $j$ at time $t$ and let $h_{i t}$ denote a health shock affecting $i$ at $t$. Initial wealth and other household attributes are denoted $w_{i}$ and $z_{i}$, respectively. Variables measuring the geographical and social distance between $i$ and $j$ are denoted $d_{i j}$; they are time-invariant. We estimate a regression of the form:

$$
\begin{aligned}
\tau_{i j t}= & \alpha_{0}+\alpha_{1}\left(h_{i t}-h_{j t}\right)+\alpha_{3}\left(w_{i}-w_{j}\right) \\
& +\alpha_{4}\left(z_{i}-z_{j}\right)+\alpha_{5}\left(x_{i t}+x_{j t}\right)+\alpha_{6} d_{i j}+u_{i j t}
\end{aligned}
$$

where $x_{i t} \equiv\left(h_{i t}, w_{i}, z_{i}\right)$. The parameters of interest are $\alpha_{1}$ and $\alpha_{3}$ : the first measures the effect of a health shock on transfers; and the second captures income redistribution. Equation (5) is estimated using OLS but correcting standard errors to account for the fact that the residuals are correlated across observations involving either the same $i$ or the same $j$. As explained in Fafchamps and Gubert (2007b), this correction is achieved in a manner comparable to Conley 
(1999)'s extension of White robust standard errors to spatially correlated data.

\subsection{Informal loans}

Efficient risk sharing calls for conditioning transfers only on current shocks - not on the history of past transfers. ${ }^{7}$ We may therefore expect mutual insurance contracts not to condition current transfers on past transfers. Yet, when participation constraints are binding, it has been shown elsewhere that conditioning on past transfers enlarges the set of sustainable equilibria, i.e., facilitates risk sharing (e.g. Kocherlakota 1996, Ligon et al. 2001, Foster and Rosenzweig 2001). This is because conditioning on past transfers eases participation constraints (somewhat). Fafchamps (1999) further argues that zero-interest informal loans with flexible repayment are a simple way of implementing such arrangements.

The intuition behind these theoretical results is best illustrated with an example. Imagine a neighbour asking you for money. If he asks for a small amount, you may simply give the money to him in exchange for future reciprocity. In this case, the transfer is small enough so that the participation constraint is not binding and the efficient risk sharing outcome is achieved. But if he asks for a larger amount, you will probably call the transfer a 'loan' even if you do not ask for interest and do net set a repayment deadline. Calling the transfer a loan enables you to insist on a repayment of $\$ 500$ in a not too distant future - thereby raising $E_{t \mid h_{i t}, h_{j t}}[F(t, \tau)]$ and easing participation constraint (4). If risk sharing is purely based on altruism - e.g., (4) without $E_{t \mid h_{i t}, h_{j t}}[F(t, \boldsymbol{\tau})]$ - the same reasoning does not apply because calling a transfer a loan has no effect on altruism $A_{i j}$.

Informal loans have been shown to matter in practice. Building on earlier work by Platteau and Abraham (1987) and Udry (1994), Fafchamps and Lund (2003) show that informal loans

\footnotetext{
${ }^{7}$ This follows immediately from the condition for Pareto efficient risk sharing, i.e., the equalization of marginal utilities across states of nature. Efficient risk sharing calls for consumption to depend only on aggregate income, not on past consumption (e.g. Mace 1991, Cochrane 1991, Townsend 1994).
} 
play an insurance role in the rural Philippines. Fafchamps and Gubert (2007a) further show that the repayment of such loans is itself contingent on shocks. Following our earlier discussion, these findings were interpreted as indirect evidence of self-enforcement constraints. Fafchamps and Gubert (2007a) argue that the repayment of past favours in labour can be seen as a disguised form of labour bonding. They nevertheless find no evidence of labour bonding in their data.

The above discussion suggests an indirect way of testing whether mutual insurance is grounded in altruism or self-interested reciprocity. In the absence of self-enforcement constraints, the efficient risk sharing of transitory shocks dictates that insurance transfers should only be conditional on current shocks. In this case, they can take the form of simple gifts and transfers. In the presence of self-enforcement constraints, mutual insurance transfers are more likely to take the form of informal loans. To investigate this idea, we reestimate (5) with new informal loans as the dependent variable. If these loans respond to shocks, this can be taken as indirect evidence of self-enforcement constraints.

\subsection{Persistent shocks}

History dependence may also arise in transfers, e.g., people may give less today if they have given more yesterday. History dependence could in principle be investigated directly by estimating a structural autoregressive model in which transfers today depend on transfers yesterday. While intellectually appealing, structural estimation is more susceptible to specification error, given the assumptions needed for estimation. It is also fraught with estimation problems given the data. ${ }^{8}$ For these reasons, we adopt here a reduced form approach in which we regress transfers today on present and past shocks.

We have shown that self-enforcement constraints (3) are more difficult to satisfy for persistent

\footnotetext{
${ }^{8}$ Transfers are measured with error. This introduces a source of endogeneity if lagged transfers are used as regressors. Many observations are zero, so lagged values would be inefficient instruments. Last but not least, it is unclear how consistent standard errors could be obtained in this case, given the limitations our data.
} 
shocks. If self-interested reciprocity is the basis for risk sharing and participation constraints are binding at least part of the time, persistent health shocks should be less well insured than transitory shocks. Intuitively this means that a given health shock $h_{i t}$ will induce a smaller transfer if this shock is persistent.

We consider several possibilities, depending on how inference is drawn about shock persistence. The first possibility we examine is the case when friends cannot tell, from the symptoms of the illness, how long it will last. Given the limited medical knowledge of the studied population, this is a reasonable assumption for many common symptoms, such as aches and pains, skin rash, fever, coughing, and diarrhoea. In this configuration, people observe a health shock $h_{i t}$ but they cannot predict how long the illness will last.

When mutual insurance is based on self-interest, we expect help from friends to fall over time if the illness persists because the longer the illness lasts, the more likely it is to be a persistent illness. This can be formalized as follows. Say in each period agent $i$ has a probability $\gamma$ of becoming permanently ill and a probability $\sigma$ of falling ill for one period only. Consider the inference drawn by $j$. The probability that $i$ is permanently ill is given by:

$$
\operatorname{Pr}(i \text { is permanently ill } \mid i \text { ill })=\frac{\operatorname{Pr}(i \text { is permanently ill })}{\operatorname{Pr}(i \text { ill })}=\frac{\gamma}{\gamma+(1-\gamma) \sigma}
$$

Is it in $j$ 's interest to help $i$ ? Let $v$ denote $j$ 's expected utility from the risk sharing relationship when $i$ is not permanently ill. For simplicity, assume that it takes exactly 1 period for $j$ to find a new friend/source of mutual insurance. Individual $j$ must choose between helping $i$ with a gift, the size of which is normalized to 1 , and risk having to pay 1 again next period - or 
reject $i$ and lose mutual insurance protection for one period. It is in $j$ 's interest to help $i$ if:

$$
\begin{aligned}
\frac{\gamma}{\gamma+(1-\gamma) \sigma}(-1)+\frac{(1-\gamma) \sigma}{\gamma+(1-\gamma) \sigma} v & \geq 0 \text { or } \\
\sigma v & \geq \frac{\gamma}{1-\gamma}
\end{aligned}
$$

which, for a large enough $v$ and a small enough $\gamma$, is satisfied.

Suppose that inequality (6), so that it is in $j$ 's interest to help $i$ in the first period that $i$ becomes ill. Suppose that $i$ is ill again the next period. What is now the probability that $i$ is permanently ill? Applying Bayes' theorem and simplifying a bit,${ }^{9}$ we get:

$$
\operatorname{Pr}(i \text { is permanently ill|ill twice }) \approx \frac{\gamma}{\gamma+(1-\gamma) \sigma^{2}}
$$

Since $\sigma<1$, it follows that $\operatorname{Pr}(i$ is permanently ill|ill once $)<\operatorname{Pr}(i$ is permanently ill|ill twice $)$. Now $j$ 's incentive to help $i$ is satisfied only if:

$$
\sigma^{2} v \geq \frac{\gamma}{1-\gamma}
$$

which is less likely to be satisfied. This argument can be extended to $N$ periods simply by raising $\sigma$ to the $N$ th power. We see that:

$$
\lim _{N \rightarrow \infty} \operatorname{Pr}(i \text { is permanently ill } \mid \text { ill } N \text { times in a row })=1
$$

with rapid convergence if $\sigma$ is small.

The above reasoning suggests that $j$ is less likely to assist $i$ the longer $i$ 's illness persists. To

\footnotetext{
${ }^{9}$ To be completely correct, we would have to allow for the fact that $i$ was temporarily ill the first period and became permanently ill in the second period. Adding this would only complicate the algebra without changing the conclusion.
} 
test this prediction, we add interaction terms between current and lagged health shocks:

$$
\begin{aligned}
\tau_{i j t}= & \alpha_{0}+\alpha_{1}\left(h_{i t}-h_{j t}\right)+\sum_{s=1}^{L} \alpha_{2 s}\left(h_{i t}-h_{j t}\right)\left(h_{i t-s}-h_{j t-s}\right) \\
& +\alpha_{3}\left(w_{i}-w_{j}\right)+\alpha_{4}\left(z_{i}-z_{j}\right)+\alpha_{5}\left(x_{i t}+x_{j t}\right) \\
& +\alpha_{6} d_{i j}+\sum_{s=1}^{L} \alpha_{7 s}\left(h_{i t-s}-h_{j t-s}\right)+u_{i j t}
\end{aligned}
$$

and test whether the $\alpha_{2 s}$ 's are negative and increasingly so. To avoid spurious inference, we include the $h_{i t-s}-h_{j t-s}$ terms as separate regressors. ${ }^{10}$

The second possibility we consider is that in which $i$ becomes sick during the survey round and friends can immediately tell whether $i$ 's illness will last. This would be a reasonable assumption if an accident results in permanent disability. In this case the shock is immediately known to be persistent, hence there is no waiting period during which $j$ revises his priors. As external observers, we do not observe which health shocks during the survey rounds are persistent and which are not. We can, however, infer this from the data by observing whether the person remains ill in subsequent periods.

In this case the estimated model takes the form:

$$
\begin{aligned}
\tau_{i j t}= & \alpha_{0}+\alpha_{1}\left(h_{i t}-h_{j t}\right)+\sum_{s=1}^{P} \alpha_{2 s}\left(h_{i t}-h_{j t}\right)\left(h_{i t+s}-h_{j t+s}\right) \\
& +\alpha_{3}\left(w_{i}-w_{j}\right)+\alpha_{4}\left(z_{i}-z_{j}\right)+\alpha_{5}\left(x_{i t}+x_{j t}\right) \\
& +\alpha_{6} d_{i j}+\sum_{s=1}^{L} \alpha_{7 s}\left(h_{i t+s}-h_{j t+s}\right)+u_{i j t}
\end{aligned}
$$

where the $h_{i t+s}-h_{j t+s}$ terms are again included as separate regressors to avoid spurious inference. The two regression models (7) and (8) can also be combined by including both leads and lags.

\footnotetext{
${ }^{10}$ For instance, it is conceivable that people reciprocate with a small gratitude gift in period $t+1$ when they received a gift because they were sick in period $t$. If this were the case, failing to include the lagged term may yield a spurious result.
} 
This forms the basis of our testing strategy for insurance against persistent shocks.

The third possibility is that $i$ has a permanent health shock, such as a chronic disability (Fafchamps and Kebede 2007) and we known that future reciprocity is highly unlikely - transfers are strictly in one direction. In this case altruism matters most. Let $d_{i j}$ be a measure of distance between $i$ and $j$ and assume that caring is stronger the smaller $d_{i j}$ is. Since participation constraints are unlikely to never bind in the case of long persistent shocks, the altruism model can be tested by estimating a regression of the form:

$$
\begin{aligned}
\tau_{i j t}= & \alpha_{0}+\alpha_{1}\left(h_{i t}-h_{j t}\right)+\alpha_{2}\left(h_{i t}-h_{j t}\right) d_{i j} \\
& +\alpha_{3}\left(w_{i}-w_{j}\right)+\alpha_{4}\left(z_{i}-z_{j}\right)+\alpha_{5}\left(x_{i t}+x_{j t}\right)+\alpha_{6} d_{i j}+u_{i j t}
\end{aligned}
$$

and testing whether $\alpha_{2}<0$ for permanent shocks.

To summarize, binding participation constraints imply that transfers today are decreasing in shocks yesterday. We have shown that participation constraints are unlikely to never bind for long persistent shocks. Consequently if transfers today do not fall in past shocks, this indicates that participation constraints are not binding. But this is unlikely unless people give for reasons other than anticipated future reciprocity - i.e., for altruistic reasons. This is the logic behind our test.

\section{The data}

The data come from a survey conducted in 2000 in Nyakatoke, a small Haya community situated in the Kagera Region of Tanzania. The village is mainly dependent on farming of bananas, sweet potatoes and cassava for food, while coffee is the main cash crop. A census was conducted of all 119 households, who were all interviewed 5 times at regular intervals in the course of one 
year. While everyone in the village agreed to participate in the survey, this analysis will drop 4 households because they have missing data for some of the regressions we want to run. The attrition rate was zero.

Although the data come from a single village they do show remarkable resemblance to regionally representative data. The CWIQ data, collected 3 years later in 2003, are a random sample of 2,250 households sampled carefully to represent the population of Kagera, which was estimated to be around 2 million in the last 2002 census (EDI 2004). Annex 1 shows that in terms of demographic characteristics, characteristics of the head, land ownership and ownership of various other assets there are only minor differences between the mean, spread and median in the Nyakatoke data and the CWIQ data. In terms of observables we can be confident that Nyakatoke is an average village in the Kagera Region.

In each round respondents were probed on a standard series of questions from multi-topic household panel surveys and very specifically on transfers they received from others in the village. The census nature of the data allow us to identify both the sender and the receiver.

The income of the sampled population is primarily agricultural and our survey spans exactly one agricultural cycle. The data is thus ill-suited study income dynamics and persistence in income shocks. ${ }^{11}$ But it is ideal to study frequent shocks such as health shocks, including chronic illness. In the US, for instance, Cochrane (1991) finds that health shocks lasting less than 100 days are insured, but those lasting more than 100 days are not. 100 days correspond to 2 rounds of our data. Given Nyakatoke households are poorer and have less access to formal health insurance than US households, our data are appropriate to investigate the effect of persistent illness.

\footnotetext{
${ }^{11}$ This stands in contrast with Fafchamps and Lund (2003) who also have a short panel (i.e., three rounds distributed over a nine months period) but observe large variation in non-farm income in their craft-oriented villages.
} 
De Weerdt and Dercon (2006) analyze a survey module from Nyakatoke in which respondents were asked to identify the 2 worst shocks of the past 10 years and explain how they coped with them. The results from their descriptive statistics are worth repeating here to substantiate the focus of this paper on transfers and health shocks. First, illness was, by far, the most frequently mentioned shock; followed by mortality, which arguably could be the result of illness. Secondly, risk-sharing via transfers was reported to be the most important response to these health shocks.

This paper uses data on health shocks that come from a section in the household questionnaire where we requested respondents to make a list of any new or ongoing illnesses in the household. The first health shock measure simply counts the total number of days that household members were ill for in between the survey rounds. Next, and for each household member that had been ill, we asked whether the illness had an adverse effect on the income earning capacity of the household (not at all, moderately or severely). From these responses, we constructed a dummy variable which is 1 when the household reports to have incurred a severe loss in farm or off-farm income generating activities due to illness. Restricting the definition of illness to adult illnesses does not change the results of the paper.

De Weerdt and Dercon (2006), using the same health dummy variable show how, on average, 17 working days are lost during serious health shocks (median 14 days). Except for the reduction in labour supply, another significant cost to illness is medical expenses. The average medical expenditures for severe health shocks is about US\$ 6.00, about 14 times the weekly non-food consumption per adult equivalent. A simple, univariate analysis of the relation between consumption and illness, again reported in De Weerdt and Dercon (2006), shows a consumption growth gap of 9 percentage points between households with and without health shocks. This shows also that a sustained illness shock, lasting several survey rounds is a very serious event. We measure persistence by the number of survey rounds an illness shock is sustained for. A 
one-round illness is labelled as transitory, while an illness sustained for 2 rounds or more is considered increasingly persistent.

Disability data come from the household roster section of the questionnaire, where for each household member over 15 we probed for permanent disabilities. The term "hajiwezi' was used in Swahili, which literally means "cannot take care of him or herself' and indicates a permanent state of dependence on others, even in simple daily activities, because of old age, or a physical or mental handicap.

Kinship data were collected by an extensive module in which the names of all 119 household heads in the village were pre-printed and questions were asked on the relationship between the members of both households. Other dyadic variables were constructed from classical attribute variables collected in household surveys: comparisons of wealth, demographics, characteristics of the household head, religion, geographical distance between the households and so forth. The wealth variable was constructed by valuing all land, livestock and durable goods in the household into dollar values.

Transfer data were collected in two parts of the questionnaire devoted, respectively, to incoming and outgoing transfers. All transfers and gifts reported by household $i$ as received from household $j$ are recorded in the incoming transfers section of the questionnaire. All transfers and gifts reported by household $i$ as given to household $j$ are recorded in the outgoing transfers section. According to both data sources, around $16 \%$ of the reported transfers were made in cash; the rest was made in kind. In-kind transfers were converted to their market value on the basis of prices collected through a special price questionnaire conducted at the local market in each of the five rounds. In value terms, cash transfers constitute $21 \%$ to $32 \%$ of the total depending on whether we use the outgoing or incoming transfers data. This is not surprising because incoming transfers include remittances received from outside the village, and those are 
more likely to be in cash.

For intra-village transfers, the identity of the giving and receiving households is known. We can thus form the $i j$-indexed matrix of all transfers made in each of our five survey rounds between each $i j$ pair of village households. Summary statistics for transfers between villagers and with the rest of the world are reported in Table 1, aggregated across all 5 rounds. In terms of averages, there is little discrepancy between what is reported by $i$ as incoming transfers from $j$ and what is reported by $j$ as outgoing transfer to $i$. Both show that $i$ receives on average around 15 dollars a year through 11 or 12 transactions. Using the dyadic data we conducted a $t$-test to formally test the equality of the transfer data originating from the income and outgoing transfer sections of the questionnaire. The difference is not statistically significant. ${ }^{12}$ As can be expected from this, the conclusions of this paper do not change whether we use data from the incoming or outgoing transfers sections - or some combination of the two. ${ }^{13}$

Table 1 further shows that transfers received from outside the village are less frequent than intra-village transfers: 3 per year as opposed to 11 per year. Across the 115 households, transfers from outside the village are larger on average. But this is primarily due to a few observations with large outside transfers. The median transfer from outside is in fact lower than that of intra-village transfers.

The survey also collected detailed data on labour transfers and all new informal loans between villagers. Labour values are imputed using the going wage rate in each round. As we see from Table 1, labour transfers are rare and negligible in magnitude. Adding them to transfers in cash and kind does not change the results reported in the remainder of this paper. We will

\footnotetext{
${ }^{12}$ This finding does not depend on whether we pool transfers across rounds or on whether we restrict the test to observations where there is at least one positive value (either given or received).

${ }^{13}$ We experimented with different ways aggregating the data from the incoming and outgoing transfers sections. One possibility is to take the average of what $i$ stated giving to $j$ and $j$ stated giving to $i$. Another possibility is to assume that if $i$ reports giving a transfer to $j$, but $j$ does not report receiving one from $i$ then $j$ erroneously omitted to report the transfer to the interviewer. In this case we take the maximum of the reported incoming and outgoing transfers. Regression results are robust to these alternative ways of measuring transfers.
} 
not discuss them further. The average value of new loans is reported in the right-hand panel of Table 1. Loans are smaller in magnitude and much less frequent than transfers. There is also sizeable disagreement between the loans respondents report having received and the loans they report having given. This must be kept in mind when analyzing the loan data.

Table 2 presents descriptive statistics for time invariant household variables. Wealth is measured as the total value of assets, expressed here in US\$ to facilitate interpretation. Household composition and key characteristics of the household head are reported as well. We see that the surveyed population is fairly diverse in terms of religious affiliation and clan membership. There are 3 religions and 25 different clans in the village. The largest clan contains $20 \%$ of the population while 10 households have no clan mates living in the community.

Information on transfers and illness shocks was collected for each household in each survey round and is summarized in Table 3 . We see that the absolute value of the transfers received by the average household in between the survey rounds (2-3 months) is a little under 3 US\$, with a median close to 1 US $\$$. On average, $17 \%$ of surveyed households had at least one serious spell of illness since the last visit of the survey team. The average number of illness days is 8 with a maximum of 90 . With average medical expenditure during an illness spell around US $\$ 6.00$, these transfers are significant.

Nyakatoke has a number of membership based indigenous insurance association. These are associations of people who have an explicit agreement to help each other in a specified way when well-defined events occur. They have come into existence without any outside assistance, advice or funding and mainly cover funeral and hospitalization expenses. Most households are members of such groups. Their history and economics of these groups are studied at length in De Weerdt (2001) and De Weerdt, Dercon, Bold and Pankhurst (2007). The modus operandi of these indigenous insurance groups are very different compared to the loose network connections 
we study in this paper. For example, contrary to the more fluid networks, these groups have membership lists written down on paper, very explicit contribution rules and well-defined events when very precise payouts are due. These rules can be hypothesized to help alleviate the enforcement constraints that otherwise plague informal insurance. Important for this paper is that some groups provide specific hospitalization insurance, contributing a fixed amount of money to a member who spends at least one night at the hospital. The amount is not linked to the costs of the stay (reducing moral hazard issues) and there is no payout in the event the member is ill, but not hospitalized (hospitalization being a very monitorable event). Households spend an average of 0.7 days in hospital between rounds (median 0) and Table 3 shows that the average payout from hospitalization insurance groups amounts to $\$ 0.7$.

Obviously the clear rules of these insurance groups create hugely different dynamics compared to the workings of the network connections that are the topic of this paper. It would certainly be inappropriate to address such vastly different institutions in the same analysis - unless in a comparative analysis, which would be beyond the scope of this paper. Nevertheless we will control for them by specifically allowing dyads that share a group link to have a different relation between health shocks and subsequent transfers (essentially by including the interaction between health shocks and group links as a regressor).

Summary statistics on all dyadic variables are presented in Table 4. In this Table the unit of observation is an $i j$-pair of households in period $t$. Since transfers are directional - i.e., they can flow from $j$ to $i$ or from $i$ to $j$ - the dyadic regression analysis includes each pair of households twice: as an $i j$-pair and as a $j i$-pair. The total number of dyadic observations is thus $5 N(N-1)=65550$ since $N=115$. By construction the mean of all differences is zero since each difference appears twice - e.g., as $x_{i t}-x_{j t}$ and as $x_{j t}-x_{i t}$.

Averaged over all possible household pairs and time periods, the average transfer is quite 
small - around 3US cent. This is hardly surprising given that there are no transfers between most pairs for most time periods. We have already discussed the variables entering the dyadic regression as sums and differences so we need not discuss them further. Proximity variables appear at the bottom of Table 4. Distance is the geographical distance in meters between the main residence of the two households. The pair of households is defined to be close kin if they have a parent-child or sibling relationship. Only $1.6 \%$ of household pairs fall into this category. The 'other blood relative' dummy captures other family ties. We also include same clan and same religion dummies.

Blood relation is strongly associated with inter-household transfers. $34 \%$ of all transfers take place between related households even though they only represent $6 \%$ of all recorded pairs. Transfers among kin represent $43 \%$ of the combined value of all transfers. Roughly one third of kin-related pairs make at least one transfer to each other during the survey year, while this is only $5 \%$ for non kin-related pairs. Local exogamy is practiced, reducing concerns that the institution of marriage is used to form kinship bonds within the village with risk-sharing in mind.

\section{Empirical results}

We begin by estimating regression model (5). Results are presented in Table 5 . The dependent variable is the $\log ($ transfers received +1$)$, with transfers converted to US\$. These are gross transfers. In other words, a gift from $j$ to $i$ at time $t$ is recorded as $\tau_{i j}$ while another (perhaps reciprocal) gift from $i$ to $j$ at $t$ is recorded as $\tau_{j i}$ with $\tau_{i j} \neq \tau_{j i}$.

Two versions of the regression are reported. The first one uses the illness dummy as shock variable; the second uses the number of illness days. To test for robustness, we also experiment with an alternative shock definition that adds the death of a household member to the illness 
shock dummy. Very similar results obtain so they are omitted here to save space.

Distance variables $d_{i j}$ include geographical distance in meters; a dummy indicating whether any member of $i$ and $j$ have a kinship bond; whether $i$ and $j$ are in the same clan; and if $i$ and $j$ share the same religion. Given that the dependent variable is in log, wealth enters the regression in $\log$ form as well. A vector of household characteristics are added as control variables $z_{i}$. They include the age, gender, and education of the household head, and household composition variables. As explained earlier, $z_{i}$ variables appear twice - as sums and as differences. Since we control for demographic characteristics and the age of the household head, the results control for the generational set-up of each dyad.

Regression results are presented in Table 5. All reported $t$-values are based on robust standard errors corrected for dyadic interdependence across observations. We find that transfers are associated with a difference in reported health shocks: the coefficient of the difference in health shock variable is significant in both regressions. Proximity variables are very significant. People with kinship links, from the same clan, sharing the same religion and who live close to each other remit more to each other, even after controlling for illness shocks. We see that people who are in the same insurance group remit more to each other in general, but their remittances in response to illness do not follow a different pattern (interaction term is not significant). ${ }^{14}$

What can these regressions tell us about the binding self-enforcement constraints? First, note that $\alpha_{3}$, the coefficient of the wealth difference $w_{i}-w_{j}$, is negative, implying that household $i$ receives less on average if it has more assets than household $j$. This finding is consistent with redistribution from the rich to the poor and is inconsistent with patronage and the kind of asymmetrical risk sharing hypothesized by Fafchamps (1999).

Second, we re-ran all regressions using as dependent variable all new informal loans between

\footnotetext{
${ }^{14}$ We also estimated the model with membership in an insurance group added to the $z_{i}$ vector of controls that enter the regression in sum and difference. This does not change any of the results presented in this paper.
} 
villagers. Regressors are identical to those reported in Table 5. Results are not reported here to save space. Contrary to the predictions of the quasi-credit model, we find that new loans are not responsive to illness shocks. This is true whether we use as dependent variable the loans reported as given, the loans reported as received, or a combination of the two. This finding stands in contrast with results reported by Fafchamps and Lund (2003) for the Philippines. We do the same with labour transfers as the dependent variable. We again find no evidence that such transfers respond to health shocks. If we combine transfers, labour transfers, and new loans into a single 'flow of funds and services' variable, we obtain results that are by and large similar to those reported for transfers alone. This is not entirely surprising but it confirms that new loans and labour transfers do not offset the insurance effect of gifts. Taken together, these findings provide no evidence supporting the limited commitment model.

Third, we test whether the persistence of a shock affects the extent to which it is insured. As explained above, the limited commitment predicts the level of insurance to be inversely related to the persistency of the shock. To this effect we estimate regression models (7) and (8) as well as the combined model. Given that we only have five data rounds in all, we experiment with one and two lags or leads. Using more leads and lags rapidly depletes the sample size as we lose time periods.

Estimation results are summarized in Table 6 for transfers. Similar regressions were estimated for labour transfers and new loans but the results are omitted as there is no evidence that they respond to illness shocks. Focusing on transfers, we see from Table 6 that nearly all interaction terms are not significant while $\alpha_{1}$, the health shock coefficient remains significant in the first four regressions. One interaction coefficient is significant (the two-lead illness interaction term in column 6 of panel 1). But this is probably a false positive: the coefficient is not significant in other, more sparsely constructed regressions, and it is also not significant 
if we change the definition of the illness variable. There is therefore no robust evidence that persistent health shocks are less well insured than transitory ones. This is inconsistent with the self-interested reciprocity model.

Fourth, we test whether permanent shocks, where the role of the donor and recipient are unlikely to be reversed, are insured. The first column of Table 7 shows that households with permanently disabled members do indeed receive more transfers. The second column show that the bulk of such transfers are between kin-related households. This is evidence in favour of the altruism model. The altruism model is further supported by an alternative specification of Table 7 (not shown) where the wealth difference is interacted with the kinship dummy. The interaction term is significant $(t=2.70)$ suggesting that redistributive transfers occur between kin.

To summarize, we find none of the tell-tale signs that insurance transfers follow reciprocal risk sharing arrangements among self-interested individuals: insurance remittances do not occur through informal loans; transfers are not regressive; and they do not fall when shocks are repeated over time. In contrast, we do find evidence to support the altruism model with unreciprocated transfers occurring between kin.

\section{Discussion}

We have examined how informal transfers and informal loans respond to reported health shocks, looking for tell-tale signs of limitations imposed by reciprocal arrangements among self-interested individuals. We have found none of these tell-tale signs, but several of our findings are consistent with altruism or social norms. How convincing is this evidence?

One source of concern is that the health status of respondents and their families is based on self-reported illness and therefore subject to response bias. Self-reported illness has been noted

to rise with wealth. This has been interpreted as implying that poor individuals cannot afford 
to be ill and stop work. Consequently they fail to acknowledge - to themselves and enumerators - bouts of illness that would drive more prosperous households off work. In our regressions we control for wealth so this by itself is not too much of a concern.

More worrisome is the possibility that surveyed households report illness only when it is insured. If illnesses that do not trigger transfers are under-reported, the coefficient of the health shock variable $\left(h_{i t}-h_{j t}\right)$ in Table 5 would be overestimated. To investigate this possibility, regressions were estimated using as dependent variable either the transfers that $i$ reported received from $j$, or the transfers that $j$ reported giving to $i$. The two reports often differ, suggesting the presence of recall bias. If $i$ is more likely to report an illness if $i$ also reports receiving something from $j$, then the two sets of results should differ. As indicated earlier, they do not. Furthermore, $23 \%$ of households who report an illness shock do not report receiving a transfer, implying that it is at least possible for respondents to report an illness without receiving anything.

Response bias is most problematic for our comparison of persistent versus temporary health shocks in Table 6. If persistent health deficits are not well insured, surveyed households may not report them. For instance, they may not report permanent disability as an illness. Using data collected in rural Ethiopia, Fafchamps and Kebede (2007) find that a significant proportion of rural dwellers suffer from some kind of disability, but they tend not to be regarded as illness since they are permanent conditions. To overcome these problems we use an alternative measure, which counts the number of people on the household roster who are categorized as 'unable to take care of themselves'. Table 7 shows that households with such members are net recipients of transfers, especially from kin.

While these observations provide some solace, they do not constitute ironclad evidence that our results are not overestimated due to response bias. Since we do not have an independent measurement of health status or disability - or a valid instrument - there is little we can do to 
correct for this bias. It nevertheless remains that a significantly positive coefficient on $\left(h_{i t}-h_{j t}\right)$ indicates that transfers play some insurance role: even with a reporting bias, it still shows that at least some illnesses trigger transfers. If households only report illness when it triggers transfers, then if illness never triggered a transfer, it would never get reported, and the coefficient of $\left(h_{i t}-h_{j t}\right)$ would be zero/undermined. Furthermore, observing that (at least some) illnesses trigger transfers does not imply that households are fully insured. As seen in Table 3, over a three month period the average value of intra-village transfers received is $\$ 2.88$, while the average expenses during a serious illness bout amount to more than double that.

Some of our results are not particularly sensitive to response bias. This is particularly true of the test results based on interaction terms reported in Table 7. Even if disability is only reported when insured, our findings still show that these transfers happen among kin. The finding that kinship plays an important role in redistributive transfers is also not affected by health reporting bias.

What of other potential sources of bias? One possibility is that individuals who are better insured engage in risky behaviour - and as a result are ill more often and receive more gifts. Chiappori and Salanie (2000) test this hypothesis for car insurance in France and find no evidence of moral hazard of this kind. Their explanation is that people who obtain car insurance tend to be more risk averse and generally engage in less risky behaviour. The same reasoning would probably apply to our data. Furthermore, it is extremely unlikely that inhabitants of Nyakatoke would deliberately put their health at risk because of the uncertain prospect of receiving small monetary transfers from other villagers. Physical ability is essential to the livelihood of all Nyakatoke villagers, who are predominantly subsistence farmers.

To investigate whether our results are sensitive to unobserved heterogeneity - due to moral 
hazard or other causes - we reestimate Table 5 using pairwise fixed effects. ${ }^{15}$ In other words, we estimated models of the form:

$$
\tau_{i j t}=\alpha_{0}+\alpha_{1}\left(h_{i t}-h_{j t}\right)+\alpha_{5}\left(x_{i t}+x_{j t}\right)+\mu_{i j}+u_{i j t}
$$

where $\mu_{i j}$ is a pair-specific fixed effect. Regressors that are not time-varying naturally drop out of the regression. Results, not shown here to save space, are very similar in magnitude and significance to those reported earlier: the results in Table 5 are not an artefact of unobserved heterogeneity, not only at the household level, but even at the dyad level.

We also worry that the correction of standard errors to account dyadic dependence across residuals may not be sufficient. For instance, we cannot rule out the possibility that what $k$ gives to $m$ depends on what $i$ gives to $j$ - for instance because $k$ had to turn to $m$ because $i$ could not help him, having already helped $j$. To investigate whether this would affect inference, we reestimated results shown in Table 5 and 7 clustering standard errors at the level of the round. Results, not shown here to save space, show that this barely affects reported standard errors and does not affect inference.

\section{Conclusion}

Applying a dyadic regression approach to detailed panel data from a Tanzanian village, we have found that inter-household transfers respond to reported illness, indicating they serve an insurance role. Building on the work of Platteau and Abraham (1987), Fafchamps (1999) shows that informal loans with no set repayment date and no interest charge can be seen as a simple way of introducing incentive-compatible time dependence in self-enforceable mutual insurance

\footnotetext{
${ }^{15}$ Given the small number of time periods, we cannot reliably estimate Table 6 with fixed effects. In Table 7 the main variable of interest is time-invariant, so also not suitable for dyadic fixed effects.
} 
arrangements. Based on this, we expect informal loans to respond to illness shocks, particularly with friends and relatives. This is indeed what Fafchamps and Lund (2003) report. ${ }^{16}$ In contrast, we find no relationship between reported illness and informal loans from other villagers.

In models of reciprocal risk sharing among self-interested individuals, binding limited commitment constraints generate time dependence in transfers (e.g. Kocherlakota 1996, Ligon et al. 2001). The responsiveness of transfers to shocks erodes with past assistance: the more one has received in the past, the less one can expect to receive in the future in response to a shock of similar magnitude. Self-interest implies that individuals cannot constantly be assisted by others, as would be required in the case of persistent or chronic illness. This is not what we find: there is no evidence that the sensitivity of current transfers to reported illness shocks falls with past illness, although this result is potentially vulnerable to response bias. We also find net transfers to households with disabled members. The occurrence of such transfers depends crucially on a kinship link. Finally, we find that transfers flow systematically from wealthy to poor households, a finding which also contradicts limited commitment models with wealth asymmetry (e.g. Platteau 1995, Fafchamps 1999).

These findings are difficult to reconcile with models of risk pooling with binding self-enforcement constraints. We find none of the tell-tale signs of binding self-enforcement constraints, such as quasi-credit, reduced transfers for persistent shocks, and systematic transfers from the poor to the rich as hypothesized by Fafchamps (1999). This conclusion seems to contradict much of the literature to date which has emphasized the role of anticipated reciprocity in enforcing risk sharing arrangements among self-interested, opportunistic individuals.

\footnotetext{
${ }^{16}$ See also Udry (1994) and Fafchamps and Gubert (2007a) for similar evidence on loan repayment.
} 


\section{References}

Akresh, R. (2004), Risk, Network Quality, and Family Structure: Child Fostering Decisions in Burkina Faso. (mimeograph).

Altonji, J. G., Hayashi, F. and Kotlikoff, L. J. (1997). "Parental Altruism and Inter Vivos Transfers: Theory and Evidence.", Journal of Political Economy, 105(6):1121-66.

Azam, J. P. and Gubert, F. (2006). "Migrants' Remittances and the Household in Africa: A Review of Evidence.", Journal of African Economies, 15(Supplement 2):426-62.

Bala, V. and Goyal, S. (2000). "A Non-Cooperative Model of Network Formation.", Econometrica, 68(5):1181-1229.

Bloch, F., Genicot, G. and Ray, D. (2004), Social Networks and Informal Insurance. (mimeograph).

Bramoulle, Y. and Kranton, R. (2005), Risk-sharing Networks. (mimeograph).

Cabrales, A., Calvo-Armengol, A. and Jackson, M. O. (2003). "La Crema: A Case Study of Mutual Fire Insurance.", Journal of Political Economy, 111(2):425-58.

Case, A., Paxson, C. and Ableidinger, J. (2003), Orphans in Africa. (mimeograph).

Case, A. and Deaton, A. (1998). "Large Cash Transfers to the Elderly in South Africa.", Economic Journal, 108(450):1330-61.

Chiappori, P.-A. and Salanie, B. (2000). "Testing for Asymmetric Information in Insurance Markets.", Journal of Political Economy, 108(1):56-78.

Coate, S. and Ravallion, M. (1993). "Reciprocity Without Commitment: Characterization and Performance of Informal Insurance Arrangements.", J. Dev. Econ., 40:1-24. 
Cochrane, J. H. (1991). "A Simple Test of Consumption Insurance.”, J. Polit. Econ., 99(5):957976.

Comola, M. (2007), The Network Structure of Informal Arrangements: Evidence from Rural Tanzania. (mimeograph).

Conley, T. (1999). "GMM Estimation with Cross-Sectional Dependence.", Journal of Econometrics, 92(1):1-45.

Cox, D. and Fafchamps, M. (2007), Extended Family and Kinship Networks., Handbook of Development Economics, Vol. 4, T. Paul Schultz and John Strauss (eds.), Elsevier, Amsterdam. (forthcoming).

Dawkins, R. (1989), The Selfish Gene, Oxford University Press, Oxford.

De Weerdt, J. (2001), Community Organisations in Rural Tanzania: A Case Study of the Community of Nyakatoke, Bukoba Rural District, EDI. available at http://www.ediafrica.com/research/joachim.

De Weerdt, J. (2004), Risk-Sharing and Endogenous Network Formation., Insurance against Poverty, Stefan Dercon (ed.), UNU-WIDER Studies in Development Economics, Oxford University Press, Oxford, pp. 197-216.

De Weerdt, J. and Dercon, S. (2006). "Risk-Sharing Networks and Insurance Against Illness.", Journal of Development Economics, 81(2):337-56.

De Weerdt, J., Dercon, S., Bold, T. and Pankhurst, A. (2007), Membership-based Indigenous Insurance Associations., Membership Based Organisations of the Poor, Martha Chen, Renana Jhabvala, Ravi Kanbur, Carol Richards (eds.), Routledge., London. 
Dercon, S., De Weerdt, J., Bold, T. and Pankhurst, A. (2006). "Group-Based Funeral Insurance in Ethiopia and Tanzania.", World Development, 34(4):685-703.

Duflo, E. (2003). "Grandmothers and Granddaughters: Old-Age Pensions and Intrahousehold Allocation in South Africa.", World Bank Economic Review, 17(1):1-25.

EDI (2004), Kagera Rural CWIQ: Baseline Survey on Poverty, Welfare and Services in Kagera Rural Districts. available at www.edi-africa.com/research/cwiq

Ellsworth, L. (1989), Mutual Insurance and Non-Market Transactions Among Farmers in Burkina Faso, University of Wisconsin. Unpublished Ph.D. thesis.

Evans, D. (2004), Orphans and Schooling in Africa: A Longitudinal Analysis. (mimeograph).

Evans, D. (2004), The Spillover Impacts of Africa's Orphan Crisis. (mimeograph).

Fafchamps, M. (1999). "Risk Sharing and Quasi-Credit.", Journal of International Trade and Economic Development, 8(3):257-278.

Fafchamps, M. (2003), Rural Poverty, Risk and Development, Edward Elgar Publishing, Cheltenham (UK).

Fafchamps, M. and Lund, S. (2003). "Risk Sharing Networks in Rural Philippines.", Journal of Development Economics, 71:261-87.

Fafchamps, M. and Gubert, F. (2007a). "Contingent Loan Repayment in the Philippines.", Economic Development and Cultural Change, 55(4):633-67.

Fafchamps, M. and Gubert, F. (2007b). "The Formation of Risk Sharing Networks.", Journal of Development Economics, 83(2):326-50. 
Fafchamps, M. and Kebede, B. (2007), Subjective well-being, disability and adaptation: A case study from rural Ethiopia, Oxford University and University of East Anglia. Paper presented at the Global Poverty Research Group (GPRG) and Brooks World Poverty Institute (BWPI) Conference, University of Manchester, 2-4 July 2007.

Foster, A. D. and Rosenzweig, M. R. (2001). "Imperfect Commitment, Altruism and the Family: Evidence from Transfer Behavior in Low-Income Rural Areas.", Review of Economics and Statistics, 83(3):389-407.

Genicot, G. and Ray, D. (2003). "Group Formation in Risk-Sharing Arrangements.", Review of Economic Studies, 70(1):87-113.

Gubert, F. (2002). "Do Migrants Insure Those Who Stay Behind? Evidence from the Kayes Area (Western Mali).", Oxford Development Studies, 30(3):267-87.

Jackson, M. O. and Wolinsky, A. (1996). "A Strategic Model of Social and Economic Networks.", Journal of Economic Theory, 71(1):44-74.

Kimball, M. S. (1988). "Farmers' Cooperatives as Behavior Toward Risk.", Amer. Econ. Rev., $78(1): 224-232$.

Kocherlakota, N. R. (1996). "Implications of Efficient Risk Sharing Without Commitment.", Rev. Econ. Stud., 63(4):595-609.

Krishnan, P. and Sciubba, E. (2006), Links and Architecture in Village Networks, Birkbeck Working Papers in Economics and Finance, No. 0614.

Ksoll, C. (2007), Family Networks and Orphan Caretaking in Tanzania. (mimeograph).

Ligon, E., Thomas, J. P. and Worrall, T. (2001). "Informal Insurance Arrangements in Village Economies.", Review of Economic Studies, 69(1):209-44. 
Lucas, R. E. and Stark, O. (1985). "Motivations to Remit: Evidence from Botswana.", J. Polit. Econ., 93 (5):901-918.

Mace, B. J. (1991). "Full Insurance in the Presence of Aggregate Uncertainty.", J. Polit. Econ., 99(5):928-956.

Mitrut, A., Nordblom, K., for Private Gift Transfers: Altruism or Social Norms? Theory, M. and from Romania, E. (2008). (mimeograph).

Platteau, J.-P. (1995). “An Indian Model of Aristocratic Patronage.”, Oxford Econ. Papers, 47(4):636-662.

Platteau, J.-P. and Abraham, A. (1987). "An Inquiry into Quasi-Credit Contracts: The Role of Reciprocal Credit and Interlinked Deals in Small-scale Fishing Communities.", J. Dev. Stud., 23 (4):461-490.

Rosenzweig, M. R. (1988). "Risk, Implicit Contracts and the Family in Rural Areas of LowIncome Countries.", Econ. J., 98:1148-1170.

Santos, P. and Barrett, C. (2007), Understanding the Formation of Social Networks. (mimeograph).

Townsend, R. M. (1994). "Risk and Insurance in Village India.", Econometrica, 62(3):539-591.

Udry, C. (1994). "Risk and Insurance in a Rural Credit Market: An Empirical Investigation in Northern Nigeria.", Rev. Econ. Stud., 61(3):495-526. 
Table 1: Total Transfers, Labour and New Loans Received by i (summed across all 5 rounds)

\begin{tabular}{|c|c|c|c|c|c|c|}
\hline & \multicolumn{2}{|c|}{$\begin{array}{c}\text { Transfers } \\
\text { (US\$) }\end{array}$} & \multirow{2}{*}{$\begin{array}{l}\text { Labour } \\
\text { (days) } \\
\text { (3) }\end{array}$} & \multicolumn{2}{|c|}{$\begin{array}{l}\text { New Loans } \\
\text { (US\$) }\end{array}$} \\
\hline & & $\begin{array}{l}(1) \\
\text { i reported } \\
\text { receiving } \\
\text { from j }\end{array}$ & $\begin{array}{l}\text { (2) } \\
\text { j reported } \\
\text { giving to i }\end{array}$ & & $\begin{array}{l}(4) \\
\text { i reported } \\
\text { receiving } \\
\text { from j }\end{array}$ & $\begin{array}{l}\text { (5) } \\
\text { j reported } \\
\text { giving to i }\end{array}$ \\
\hline \multirow[t]{3}{*}{ within village } & Avg of total i received & 14.42 & 14.96 & 0.50 & 5.42 & 8.72 \\
\hline & Median of total i received & 9.56 & 7.14 & 0.00 & 3.00 & 3.56 \\
\hline & Avg no. of transactions i & 10.70 & 12.23 & 0.32 & 2.38 & 3.41 \\
\hline \multirow[t]{3}{*}{ outside village } & Avg of total i received & 26.68 & $\mathrm{n} / \mathrm{a}$ & $\mathrm{n} / \mathrm{a}$ & 10.33 & $\mathrm{n} / \mathrm{a}$ \\
\hline & Median of total i received & 7.00 & $\mathrm{n} / \mathrm{a}$ & $\mathrm{n} / \mathrm{a}$ & 0.00 & $\mathrm{n} / \mathrm{a}$ \\
\hline & Avg no. of transactions $i$ & 2.63 & $\mathrm{n} / \mathrm{a}$ & $\mathrm{n} / \mathrm{a}$ & 0.72 & $\mathrm{n} / \mathrm{a}$ \\
\hline
\end{tabular}


Total assets (in US\$)

Age of household head

Number of children aged 0-5

Number of children aged 6-15

Number of male adults

Number of female adults

Male household head

Household head with primary education

Household head is catholic

Household head is lutheran

Household head is muslim

Number of observations

$\begin{array}{rrrrr}\text { Mean } & \text { St.dev. } & \text { Median } & \text { Minimum } & \text { maximum } \\ 672.54 & 971.80 & 405.46 & 0.00 & 8943.07 \\ 45.60 & 15.86 & 42 & 21 & 89 \\ 0.95 & 0.94 & 1 & 0 & 3 \\ 1.37 & 1.29 & 1 & 0 & 5 \\ 1.10 & 0.87 & 1 & 0 & 4 \\ 1.34 & 0.75 & 1 & 0 & 5 \\ 73 \% & & & & \\ 60 \% & & & & \\ 43 \% & & & & \\ 37 \% & & & & \\ 21 \% & & & & \\ 115 & & & & \end{array}$

Table 3. Transfers and health shocks

\begin{tabular}{|c|c|c|c|c|c|}
\hline & Mean & St.dev. & Median & Minimum & maximum \\
\hline Transfers received (in US\$) & 2.88 & 5.53 & 0.94 & 0 & 58.50 \\
\hline Labour received (in US\$) & 0.99 & 0.66 & 0.00 & 0 & 9.63 \\
\hline New Loans received (in US\$) & 1.08 & 3.05 & 0.00 & 0 & 30.63 \\
\hline Ilness dummy & $17 \%$ & & & 0 & 1 \\
\hline Illness days & 8.42 & 13.15 & 0 & 0 & 90 \\
\hline No. of disabled adults in $\mathrm{HH}$ & 0.20 & 0.50 & 0.00 & 0 & 3.00 \\
\hline Group hospitalisation insurance payment & 0.70 & 3.10 & 0 & 0 & 35 \\
\hline Nber of observations (hhs $x$ time periods) & 575 & & & & \\
\hline
\end{tabular}


Table 4. Descriptive statistics on dyadic regressors

\begin{tabular}{|c|c|c|c|c|c|}
\hline Transfers (LHS) & mean & sd & p50 & $\min$ & $\max$ \\
\hline Transfer received (in log transformed US\$) & 0.01 & 0.11 & 0 & 0 & 4.09 \\
\hline \multicolumn{6}{|l|}{ Difference in: } \\
\hline Illness dummy & 0.00 & 0.53 & 0 & -1 & 1 \\
\hline Illness days & 0.00 & 18.16 & 0 & -90 & 90 \\
\hline Number of disabled adults & 0.00 & 0.68 & 0 & -3 & 3 \\
\hline Total assets (in log transformed US\$) & 0.00 & 1.73 & 0 & -9.10 & 9.10 \\
\hline Age of household head & 0.00 & 22.43 & 0 & -68 & 68 \\
\hline Number of children aged 0-5 & 0.00 & 1.41 & 0 & -4 & 4 \\
\hline Number of children aged 6-15 & 0.00 & 1.79 & 0 & -5 & 5 \\
\hline Number of male adults & 0.00 & 1.25 & 0 & -4 & 4 \\
\hline Number of female adults & 0.00 & 1.02 & 0 & -5 & 5 \\
\hline Male household head dummy & 0.00 & 0.63 & 0 & -1 & 1 \\
\hline Household head with primary education & 0.00 & 0.70 & 0 & -1 & 1 \\
\hline \multicolumn{6}{|l|}{ Sum of: } \\
\hline Illness dummy & 0.34 & 0.53 & 0 & 0 & 2 \\
\hline Illness days & 16.83 & 18.99 & 14 & 0 & 175 \\
\hline Number of disabled adults & 0.40 & 0.67 & 0 & 0 & 5 \\
\hline Total assets (in log transformed US\$) & 11.93 & 1.71 & 12.08 & 0 & 17.31 \\
\hline Age of household head & 91.20 & 22.23 & 89 & 44 & 174 \\
\hline Number of children aged 0-5 & 2.01 & 1.40 & 2 & 0 & 8 \\
\hline Number of children aged 6-15 & 2.65 & 1.78 & 3 & 0 & 10 \\
\hline Number of male adults & 2.22 & 1.24 & 2 & 0 & 8 \\
\hline Number of female adults & 2.59 & 1.01 & 2 & 0 & 8 \\
\hline Male household head dummy & 1.46 & 0.62 & 2 & 0 & 2 \\
\hline Household head with primary education & 1.20 & 0.69 & 1 & 0 & 2 \\
\hline \multicolumn{6}{|l|}{ Proximity: } \\
\hline Distance & 523.23 & 312.16 & 463.2 & 14.4 & 1737.6 \\
\hline kinship dummy & $5.6 \%$ & & & & \\
\hline Same clan dummy & $9.6 \%$ & & & & \\
\hline Same religion dummy & $35.3 \%$ & & & & \\
\hline Insurance group link & $11.3 \%$ & & & & \\
\hline Number of observations (pairs $x$ time period) & 65550 & & & & \\
\hline
\end{tabular}


Difference in:

Illness dummy/illness days

Wealth (log)

$\mathrm{HH}$ head has primary schooling

N. children aged 0-5

N. children aged 6-15

N. male adults

N. female adults

Age of Household head

Sum in:

Female household head dummy

Illness dummy/illness days

Wealth

$\mathrm{HH}$ head has primary schooling

N. children aged 0-5

N. children aged 6-15

N. male adults

N. female adults

Age of Household head

Proximity:

Female household head dummy

Kinship dummy

Same clan dummy

Same religion dummy

Geographical distance

Insurance group link

Insurance group link $x$ diff. illness var.

Intercepts:
Round 1
Round 2
Round 3
Round 4
Round 5
Number of observations

\begin{tabular}{|c|c|c|c|}
\hline \multicolumn{2}{|c|}{ Illness dummy } & \multicolumn{2}{|c|}{ Illness days } \\
\hline coef. & t-stat & coef. & t-stat \\
\hline 3.58 & 3.44 & 0.07 & 2.15 \\
\hline-1.29 & -3.43 & -1.37 & -3.69 \\
\hline-1.26 & -1.33 & -1.39 & -1.49 \\
\hline 0.16 & 0.32 & 0.11 & 0.21 \\
\hline-0.96 & -2.58 & -1.02 & -2.73 \\
\hline 1.40 & 2.12 & 1.32 & 2.02 \\
\hline-2.66 & -2.54 & -2.74 & -2.58 \\
\hline-0.12 & -3.98 & -0.13 & -4.24 \\
\hline-2.39 & -1.95 & -2.42 & -2.01 \\
\hline 1.81 & 1.61 & 0.00 & 0.09 \\
\hline 1.69 & 2.90 & 1.65 & 2.83 \\
\hline-0.03 & -0.02 & -0.12 & -0.10 \\
\hline 0.32 & 0.47 & 0.33 & 0.48 \\
\hline-0.66 & -1.61 & -0.67 & -1.62 \\
\hline 1.14 & 1.01 & 1.15 & 1.01 \\
\hline 3.20 & 2.75 & 3.25 & 2.79 \\
\hline 0.06 & 1.68 & 0.06 & 1.57 \\
\hline 2.05 & 0.92 & 2.05 & 0.93 \\
\hline 19.07 & 7.58 & 19.04 & 7.57 \\
\hline 12.86 & 4.91 & 12.81 & 4.88 \\
\hline 7.22 & 5.99 & 7.20 & 5.98 \\
\hline-0.02 & -7.41 & -0.02 & -7.42 \\
\hline 7.87 & 3.24 & 7.87 & 3.21 \\
\hline 7.22 & 1.34 & 0.22 & 1.55 \\
\hline-24.41 & -3.19 & -22.92 & -3.01 \\
\hline-27.93 & -3.63 & -26.46 & -3.43 \\
\hline-23.52 & -3.15 & -22.20 & -2.97 \\
\hline-22.64 & -3.44 & -21.58 & -3.25 \\
\hline-24.79 & -3.25 & -23.49 & -3.07 \\
\hline 65550 & & 65550 & \\
\hline
\end{tabular}

The dependent variable is the log of all transfers received +1 .

All coefficients are multiplied by 1000 . All t-statistics based on dyadic robust standard errors. 


\begin{tabular}{|c|c|c|c|c|c|c|c|c|c|c|c|c|}
\hline \multirow{2}{*}{ LHS = ILLNESS DUMMY: } & \multicolumn{2}{|c|}{ (1) } & \multicolumn{2}{|c|}{$(2)$} & \multicolumn{2}{|l|}{ (3) } & \multicolumn{2}{|c|}{ (4) } & \multicolumn{2}{|c|}{ (5) } & \multicolumn{2}{|c|}{ (6) } \\
\hline & & & & & & & & & & & & \\
\hline Illness variable & coef. & t-stat & coef. & t-stat & coef. & t-stat & coef. & t-stat & coef. & t-stat & coef. & t-stat \\
\hline Illness variable t & 4.53 & 2.80 & 7.50 & 3.81 & 3.81 & 2.59 & 3.59 & 2.19 & 2.65 & 1.18 & 7.50 & 1.38 \\
\hline Illness variable t-1 & 2.00 & 1.12 & 0.03 & 0.01 & & & & & 0.98 & 0.51 & 1.31 & 0.58 \\
\hline Illness variable t-2 & & & 0.00 & 0.00 & & & & & & & 0.75 & 0.30 \\
\hline Illness variable $t+1$ & & & & & 0.37 & 0.29 & -1.64 & -1.05 & 1.62 & 0.91 & 2.75 & 1.32 \\
\hline Illness variable $\mathrm{t}+2$ & & & & & & & -0.29 & -0.15 & & & 3.78 & 1.35 \\
\hline Illness variable t $x(t-1)$ & -0.44 & -0.13 & 1.66 & 0.22 & & & & & 2.61 & 0.68 & 6.58 & 0.41 \\
\hline Illness variable t x (t-2) & & & -3.31 & -0.74 & & & & & & & -5.63 & -0.72 \\
\hline Illness variable $\mathrm{t} x(\mathrm{t}+1)$ & & & & & -1.09 & -0.36 & 3.76 & 0.67 & -1.70 & -0.42 & 3.78 & 0.47 \\
\hline Illness variable $\mathrm{t} x(\mathrm{t}+2)$ & & & & & & & -2.50 & -0.83 & & & -10.99 & -2.23 \\
\hline Number of observations & 52,440 & & 39,330 & & 52,440 & & 39,330 & & 39,330 & & 13,110 & \\
\hline & (8) & & (9) & & (10) & & $(11)$ & & $(12)$ & & $(13$ & \\
\hline \multicolumn{13}{|l|}{ LHS = ILLNESS DAYS: } \\
\hline Illness variable t-1 & 0.03 & 0.61 & 0.01 & 0.08 & & & & & 0.02 & 0.32 & 0.08 & 0.87 \\
\hline Illness variable t-2 & & & -0.04 & -0.67 & & & & & & & -0.14 & -1.77 \\
\hline Illness variable $\mathrm{t}+1$ & & & & & 0.04 & 1.17 & 0.04 & 1.06 & 0.05 & 0.96 & 0.10 & 0.87 \\
\hline Illness variable $t+2$ & & & & & & & -0.04 & -0.76 & & & 0.10 & 1.15 \\
\hline \multicolumn{13}{|l|}{ Interaction terms: } \\
\hline Illness variable $\mathrm{t} \times(\mathrm{t}-1)$ & 0.00 & -1.14 & 0.00 & -0.74 & & & & & 0.00 & -1.49 & -0.01 & -1.40 \\
\hline Illness variable t x (t-2) & & & 0.00 & 0.80 & & & & & & & 0.01 & 1.28 \\
\hline Illness variable $t \times(t+1)$ & & & & & 0.00 & -0.29 & 0.00 & -1.38 & 0.00 & 1.41 & -0.01 & -0.90 \\
\hline Illness variable $\mathrm{t} x(\mathrm{t}+2)$ & & & & & & & 0.00 & 0.65 & & & 0.00 & 0.01 \\
\hline Number of observations & 52,440 & & 39,330 & & 52,440 & & 39,330 & & 39,330 & & 13,110 & \\
\hline
\end{tabular}

The dependent variable is the log of all transfers received +1 .

All coefficients are multiplied by 1000 . All t-statistics based on dyadic robust standard errors.

Regressions include controls for sums and differences of the household's wealth, demographics and head characteristics, as well as kinship, clan, neigbourhood and insurance group links. 
Table 7. Transfers and Permanent Shocks

\section{Permanent Shocks}

N. of disabled adults

- " - $\quad$ x kinship dummy

- " - $\quad$ x geographical distance

- " - $\quad x$ wealth difference

\section{Difference in:}

Wealth (log)

$\mathrm{HH}$ head has primary schooling

$\mathrm{N}$. children aged 0-5

N. children aged 6-15

N. male adults

$\mathrm{N}$. female adults

Age of household head

Male household head dummy

Sum in:

N. disabled adults

Wealth (log)

$\mathrm{HH}$ head has primary schooling

N. children aged 0-5

N. children aged 6-15

N. male adults

$\mathrm{N}$. female adults

Age of household head

Male household head dummy

Proximity:

Kinship dummy

Same clan dummy

Same religion dummy

Geographical distance

Insurance group link

Intercepts:

Round 1

Round 2

Round 3

Round 4

Round 5 coef

3.453

$$
3.15
$$

$-1.04$

$-1.54$

0.00

$-1.00$

1.15

$-3.31$

$-0.17$

$-2.36$

1.97

1.85

$-0.19$

0.22

$-0.68$

1.01

2.78

0.03

2.05

19.04

13.02

7.15

$-0.02$

7.96

$-21.81$

$-25.31$

$-21.09$

$-20.58$

$-22.48$

65550
$-2.65$

$-1.63$

0.01

$-2.69$

1.87

$-3.12$

$-5.25$

$-1.97$

1.09

3.05

$-0.15$

0.34

$-1.63$

0.94

2.28

0.76

0.93

7.58

4.91

5.97

$-7.43$

3.28

$-2.90$

$-3.35$

$-2.83$

$-3.18$

$-3.00$ coef.

3.258

19.61

0.00

$-0.68$

$-1.07$

$-1.33$

$-0.07$

$-0.95$

1.11

$-3.34$

$-0.17$

$-2.29$

2.47

2.19

$-0.25$

0.11

$-0.69$

0.91

2.73

0.02

2.04

18.98

13.12

7.18

$-0.02$

8.07

$-24.54$

$-28.03$

$-23.81$

$-23.30$

$-25.21$

65550 t-stat

1.63

1.90

$-0.53$

$-1.21$

$-2.75$

$-1.41$

$-0.16$

$-2.58$

1.81

$-3.12$

$-5.26$

$-1.90$

1.32

2.84

$-0.20$

0.17

$-1.68$

0.85

2.20

0.49

0.92

7.60

4.92

5.93

$-7.36$

3.36

$-3.07$

$-3.50$

$-3.08$

$-3.31$

$-3.16$

Number of observations

The dependent variable is the log of all transfers received +1 .

All coefficients are multiplied by 1000 . All t-statistics based on dyadic robust standard errors. 
Annex 1

Table A1: Comparison between Nyakatoke and CWIQ data

\begin{tabular}{llrrr}
\hline Variable & dataset & mean & sd & \multicolumn{2}{c}{ median } \\
& & & & \\
\hline Anyone in HH owns watch & CWIQ & 0.445 & 0.497 & 0.000 \\
& Nyakatoke & 0.496 & 0.502 & 0.000 \\
Anyone in HH owns radio & CWIQ & 0.519 & 0.500 & 1.000 \\
& Nyakatoke & 0.383 & 0.488 & 0.000 \\
Anyone in HH owns bicycle & CWIQ & 0.400 & 0.490 & 0.000 \\
& Nyakatoke & 0.496 & 0.502 & 0.000 \\
Anyone in HH owns motorbike & CWIQ & 0.019 & 0.135 & 0.000 \\
& Nyakatoke & 0.009 & 0.093 & 0.000 \\
Anyone in HH owns car & CWIQ & 0.008 & 0.087 & 0.000 \\
& Nyakatoke & 0.000 & 0.000 & 0.000 \\
Land owned (in ha.) & CWIQ & 1.304 & 1.793 & 0.800 \\
& Nyakatoke & 1.372 & 1.259 & 0.998 \\
Household head completed primary & CWIQ & 0.514 & 0.500 & 1.000 \\
& Nyakatoke & 0.609 & 0.490 & 1.000 \\
Household head is female & CWIQ & 0.179 & 0.383 & 0.000 \\
& Nyakatoke & 0.261 & 0.441 & 0.000 \\
Age of household head & CWIQ & 42.876 & 15.543 & 40.000 \\
& Nyakatoke & 44.800 & 15.864 & 42.000 \\
Household size & CWIQ & 5.212 & 2.529 & 5.000 \\
No. of male adults & Nyakatoke & 5.200 & 2.689 & 5.000 \\
No. of female adults & CWIQ & 1.198 & 0.771 & 1.000 \\
No. of children 0-15 & Nyakatoke & 1.296 & 0.917 & 1.000 \\
Nol of children 0-5 & CWIQ & 1.263 & 0.742 & 1.000 \\
& Nyakatoke & 1.383 & 0.864 & 1.000 \\
& CWIQ & 2.749 & 2.021 & 3.000 \\
& Nyakatoke & 2.522 & 1.774 & 3.000 \\
& CWIQ & 1.139 & 1.081 & 1.000 \\
& Nyakatoke & 0.957 & 0.940 & 1.000 \\
\hline & Nyakatoke & & &
\end{tabular}

Note: - $\mathrm{N}=2250$ for CWIQ and $\mathrm{N}=115$ for Nyakatoke

- CWIQ data are a random sample of Kagera Household of 2003

- CWIQ reports and raw data are in the public domain at www.edi-africa.com/research/cwiq 